\title{
Light-driven formation of high-valent manganese oxide by photosystem II supports evolutionary role in early bioenergetics
}

Petko Chernev, ${ }^{1,2}$ Sophie Fischer, ${ }^{1}$ Jutta Hoffmann, ${ }^{1}$ Nicholas Oliver, ${ }^{1}$ Robert L. Burnap, ${ }^{3}$ Ivelina Zaharieva, ${ }^{1}$ Dennis J. Nürnberg, ${ }^{1}$ Michael Haumann, ${ }^{1}$ Holger Dau ${ }^{1 *}$

${ }^{1}$ Physics Department, Freie Universität Berlin, Arnimallee 14, 14195 Berlin, Germany

${ }^{2}$ present address: Department of Chemistry - Ångström Laboratory, Molecular Biomimetics, Uppsala University, Lägerhyddsvägen 1, 75120 Uppsala, Sweden

${ }^{3}$ Dept. of Microbiology and Molecular Genetics, Oklahoma State University, Stillwater, Oklahoma 74078-4034, United States

*Correspondence to:

Prof. Holger Dau, Email: holger.dau@fu-berlin.de

\begin{abstract}
Nature Com.: Abstract approximately 150 words)
Water oxidation and concomitant $\mathrm{O}_{2}$-formation by the $\mathrm{Mn}_{4} \mathrm{Ca}$ cluster of oxygenic photosynthesis has shaped the biosphere, atmosphere, and geosphere. It has been hypothesized that at an early stage of evolution, before photosynthetic water oxidation became prominent, photosynthetic formation of $\mathrm{Mn}$ oxides from dissolved $\mathrm{Mn}(2+)$ ions may have played a key role in bioenergetics and possibly facilitated early geological manganese deposits. The biochemical evidence for the ability of photosystems to form extended Mn oxide particles, lacking until now, is provided herein. We tracked the light-driven redox processes in spinach photosystem II (PSII) particles devoid of the $\mathrm{Mn}_{4} \mathrm{Ca}$ clusters by UV-vis and X-ray spectroscopy. We find that oxidation of aqueous $\mathrm{Mn}(2+)$ ions results in PSII-bound Mn(III,IV)-oxide nanoparticles of the birnessite type comprising 50-100 Mn ions per PSII. Having shown that even today's photosystem-II can form birnessite-type oxide particles efficiently, we propose an evolutionary scenario, which involves Mn-oxide production by ancestral photosystems, later followed by down-sizing of protein-bound Mn-oxide nanoparticles to finally yield today's $\mathrm{Mn}_{4} \mathrm{CaO}_{5}$ cluster of photosynthetic water oxidation.
\end{abstract}


bioRxiv preprint doi: https://doi.org/10.1101/2020.03.03.975516; this version posted March 5, 2020. The copyright holder for this preprint (which was not certified by peer review) is the author/funder. All rights reserved. No reuse allowed without permission.

Chernev et al, Light-driven formation of manganese oxides by photosystem II

\section{Introduction}

Nature's invention of photosynthetic water oxidation about three billion years ago (or even earlier ${ }^{1}$ ) was a breakpoint in Earth's history because it changed the previously anoxic atmosphere to today's composition with $\sim 21 \% \mathrm{O}_{2}$, practically depleting the oceans of ferrous iron and divalent manganese due to metal-oxide precipitation ${ }^{2,3}$. Water oxidation is catalyzed by a unique bioinorganic cofactor, denoted $\mathrm{Mn}_{4} \mathrm{CaO}_{5}$ according to its oxo-bridged metal core, which is bound to amino acids of the proteins of photosystem II (PSII) in the thylakoid membrane (Fig. 1) ${ }^{4-8}$. This catalyst originally developed in (prokaryotic) cyanobacteria, which were later incorporated by endosymbiosis into the ancestor of the (eukaryotic) cells of algae and plants to yield the chloroplast organelles ${ }^{9}$. The central PSII proteins as well as $\mathrm{Mn}_{4} \mathrm{CaO}_{5}$ (and its main catalytic performance features) are strictly conserved among photosynthetic organisms ${ }^{10}$.
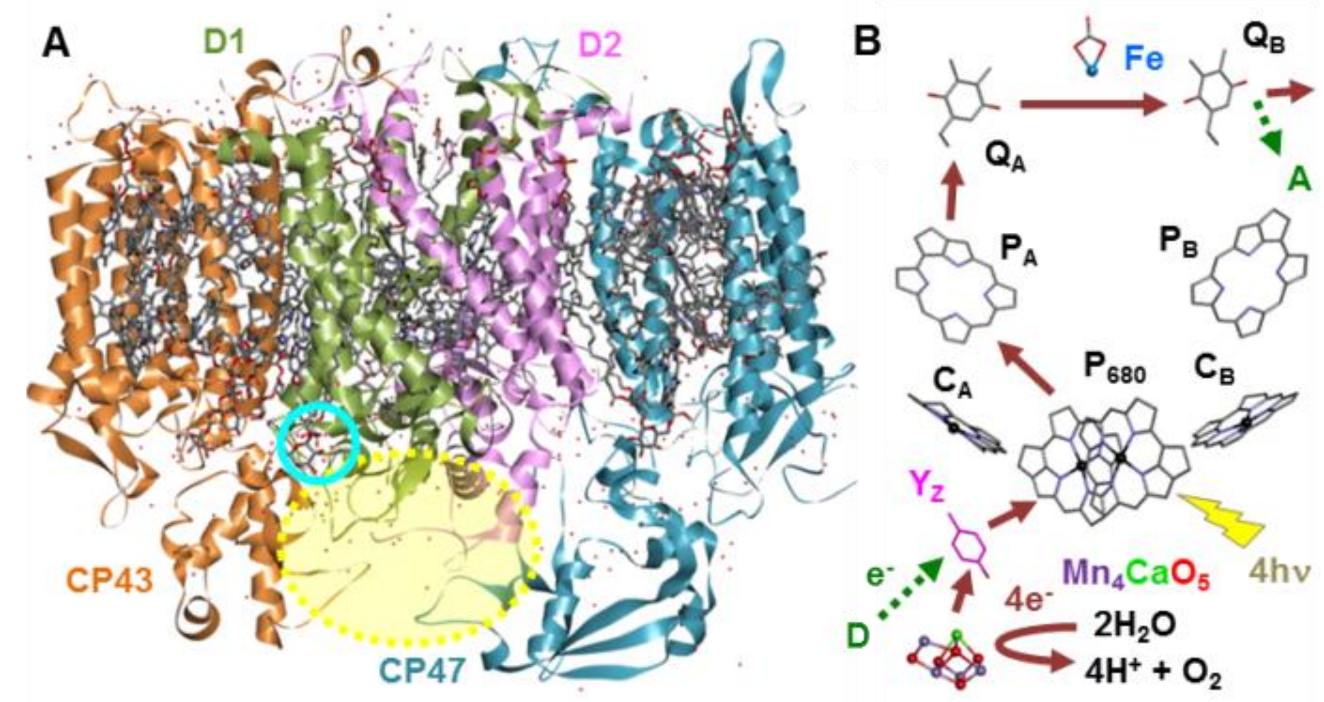

Figure 1: Structure and function of photosystem II. (A) Crystal structure of native plant PSII (PDB entry $5 \mathrm{XNL}{ }^{11}$ ). The central membrane-integral subunits with cofactors of a PSII monomer are shown (cyan circle $=\mathrm{Mn}_{4} \mathrm{CaO}_{5}$ position). Omitting extrinsic subunits $(18,24$, $33 \mathrm{kDa}$; absent in our Mn-depleted PSII) exposes a cavity (yellow). (B) Cofactors (truncated structures) for light-driven electron transfer in D1/D2 (Y $\mathrm{Y}_{\mathrm{Z}}$, tyrosine electron acceptor from $\mathrm{Mn}_{4} \mathrm{CaO}_{5} ; \mathrm{P}_{680}$, primary donor chlorophyll (chl) dimer; $\mathrm{C}_{\mathrm{A}, \mathrm{B}}$, accessory chl; $\mathrm{P}_{\mathrm{A} . \mathrm{B}}$, pheophytins; $\mathrm{Q}_{\mathrm{A}, \mathrm{B}}$, acceptor quinones; $\mathrm{Fe}$, non-heme iron with bicarbonate ligand). Green/dark-red arrows: electron transfer paths upon photo-excitation $(h v)$ of $\mathrm{O}_{2}$-evolving or Mn-depleted PSII (D/A, external electron donor/acceptor).

Native PSII operates as a light-driven oxidoreductase (Fig. 1). Upon sequential excitation with four visible-light photons, four electrons from two bound water molecules are transferred from $\mathrm{Mn}_{4} \mathrm{CaO}_{5}$ to a redox-active tyrosine $\left(\mathrm{Y}_{\mathrm{Z}}\right)$ at the donor side and then via a cofactor chain to terminal quinone acceptors at the stromal side so that two reduced quinols as well as $\mathrm{O}_{2}$ and four protons are released during each catalytic water oxidation cycle ${ }^{5,7,12-14}$. Starting from a $\mathrm{Mn}(\mathrm{III})_{3} \mathrm{Mn}(\mathrm{IV}) \mathrm{Y}_{\mathrm{Z}}$ state, the catalytic cycle involves alternate electron and proton abstraction to reach a $\mathrm{Mn}(\mathrm{IV})_{4} \mathrm{Y}_{\mathrm{Z}}{ }^{\text {ox }}$ state followed by (concomitant) $\mathrm{Mn}$ re-reduction, $\mathrm{O}-\mathrm{O}$ bond formation 
and $\mathrm{O}_{2}$ release (Fig. 1) ${ }^{15}$. The exceptionally efficient $\mathrm{Mn}_{4} \mathrm{CaO}_{5}$ catalyst has inspired development of synthetic water-oxidizing materials ${ }^{16-18}$. Among the wealth of findings on water oxidation by Mn-based catalysts, here the following two results are of particular importance: (i) Self-assembly of the $\mathrm{Mn}(\mathrm{III} / \mathrm{IV})_{4} \mathrm{CaO}_{5}$ core in PSII is a light-driven process, involving step-wise oxidation of four solvent $\mathrm{Mn}^{2+}$ ions by $\mathrm{Y}_{\mathrm{Z}}{ }^{\mathrm{ox}}$ coupled to electron transfer to the quinones ${ }^{19,20}$. (ii) Many amorphous Mn oxides of the birnessite type show significant water oxidation activity and share structural as well as functional features with the $\mathrm{Mn}_{4} \mathrm{CaO}_{5}$ core of the biological catalyst ${ }^{21-25}$.

The evolutionary route towards the present water oxidation catalyst in PSII is much debated 2,26-31. It has been hypothesized that before the evolution of oxygenic photosynthesis an ancestral photosystem eveloped the capability for light-driven oxidation of dissolved $\mathrm{Mn}^{2+}$ ions towards the $\mathrm{Mn}(\mathrm{III} / \mathrm{IV})$ level, thereby providing the reducing equivalents (electrons) needed for primary biomass formation by $\mathrm{CO}_{2}$ fixation ${ }^{32,33}$. Noteworthy, the process of continuous $\mathrm{Mn}^{2+}$ oxidation is chemically not trivial, because suitable redox potentials alone are insuficient. Because solitary Mn(III/IV) ions are not stable in aqueous solution, the ability of the photosystem to stabilize high-valent $\mathrm{Mn}$ ions by efficient formation of extended Mn (oxide) structures is pivotal. In the present study, clear experimental evidence is provided that today's PSII, depleted of its native $\mathrm{Mn}_{4} \mathrm{CaO}_{5}$ complex and the membrane-extrinsic polypeptides, can form a Mn(III/IV) oxide of the birnessite type. Aside from the implications for biological evolution, photosynthetic $\mathrm{Mn}$ oxide formation has significance in the context of recent hypotheses to account for geologic Mn deposits, for example from the early Paleoproterozoic in South Africa ${ }^{2,33}$.

\section{Results}

Spinach photosystems depleted of $\mathrm{Mn}_{4} \mathrm{CaO}_{5}$ and extrinsic polypeptides. Figure 1 shows the arrangement of protein subunits and cofactors in PSII. A recent crystallographic study has revealed that the metal-binding amino acids are similarly arranged in PSII with or without $\mathrm{Mn}_{4} \mathrm{CaO}_{5}$, with the voids in the Mn-depleted photosystem being filled by water molecules ${ }^{34}$. Only in the absence of the Mn-stabilizing extrinsic proteins, sufficient room for incorporation of a Mn oxide nanoparticle into the PSII structure may exist (Fig. 1). Therefore, we explored the ability of purified PSII, depleted of $\mathrm{Mn}_{4} \mathrm{CaO}_{5}$ and the extrinsic proteins, to form Mn-oxide species in vitro. PSII-enriched membrane particles were prepared from spinach ${ }^{35}$ and $\mathrm{Mn}$ depletion was achieved using an established protocol (see Supporting Information) ${ }^{36}$. The resulting PSII preparation was inactive in light-driven $\mathrm{O}_{2}$-evolution and $\mathrm{Mn}$ was practically undetectable, i.e., less than 0.2 Mn ions per PSII were found (Table 1). Concomitantly with Mn depletion, the three proteins bound to the lumenal side of plant PSII (the so-called extrinsic proteins of about $18 \mathrm{kDa}, 23 \mathrm{kDa}$, and $33 \mathrm{kDa}){ }^{37,38}$ were removed, as revealed by polarography, TXRF metal quantification, and gel electrophoresis (Figs. S1, S2; Tables 1, S1). 
Table 1: Metal content of PSII preparations (for details, see Table S1).

\begin{tabular}{|l|l|l|}
\hline preparation & Mn per PSII & Fe per PSII \\
\hline intact $\left(\mathrm{O}_{2}\right.$ evolving) PSII & $4 \pm 1$ & $9 \pm 2$ \\
\hline $\begin{array}{l}\text { Mn-depleted (non-O } \\
\text { evolving) PSII }\end{array}$ & $<0.2 \pm 0.2$ & $6 \pm 2$ \\
\hline $\begin{array}{l}\text { Mn-depleted PSII } \\
+250 \mu \mathrm{M} \mathrm{MnCl}_{2} \text {, dark }\end{array}$ & $7 \pm 2$ & $5 \pm 1$ \\
\hline $\begin{array}{l}\mathrm{Mn} \text {-depleted PSII } \\
+250 \mu \mathrm{M} \mathrm{MnCl}_{2}, \text { light }\end{array}$ & $65 \pm 19$ & $5 \pm 1$ \\
\hline
\end{tabular}

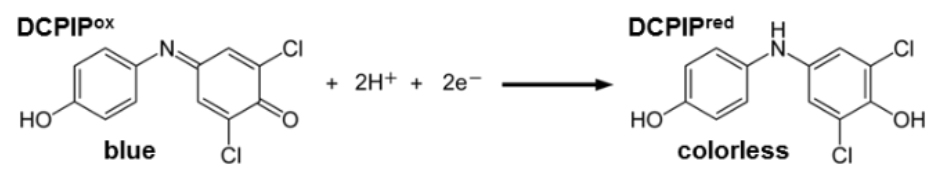

Figure 2: Oxidized and reduced DCPIP (2,6-dichlorphenol-indophenol).
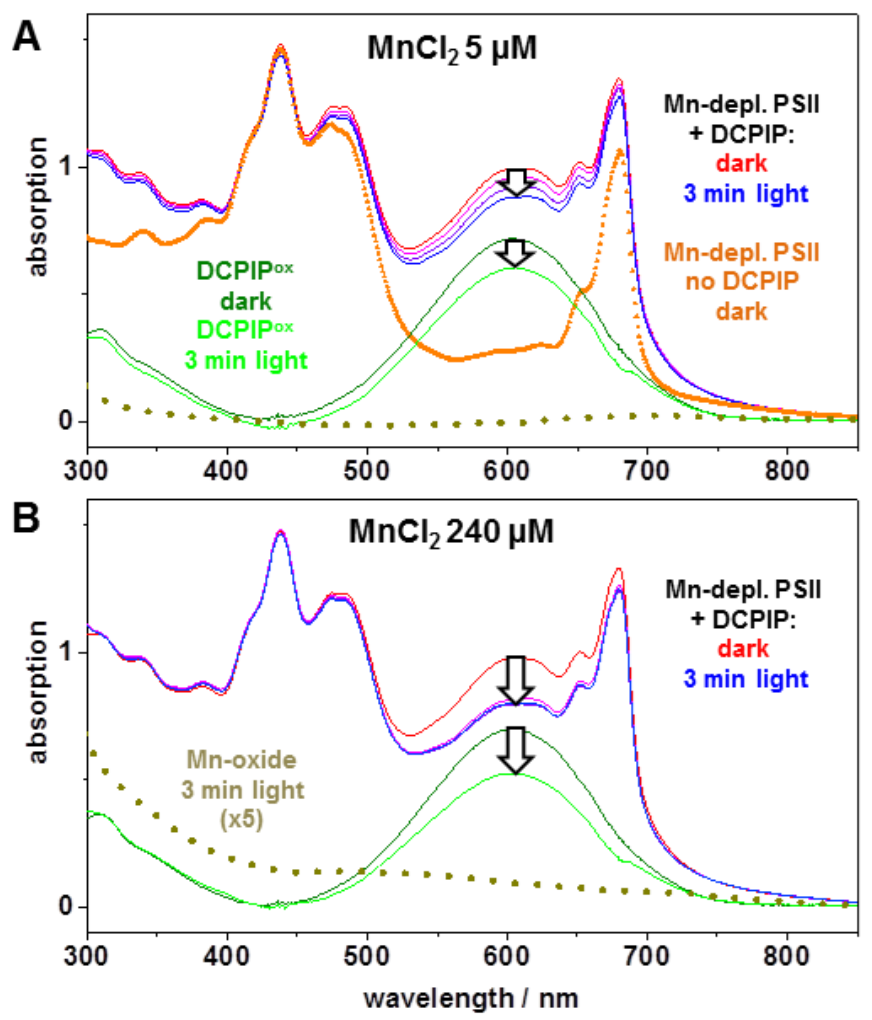

Figure 3: Light-driven redox reactions in Mn-depleted PSII tracked by optical spectroscopy. (A) and (B) show UV-vis absorption spectra. The orange line (triangles) represents a suspension of Mn-depleted PSII before addition of DCPIP $(60 \mu \mathrm{M})$ serving as artificial electron acceptor (buffer conditions: $1 \mathrm{M}$ glycine-betaine, $15 \mathrm{mM} \mathrm{NaCl}, 5 \mathrm{mM} \mathrm{CaCl} 2,5 \mathrm{mM}$ $\mathrm{MgCl}_{2}, 25 \mathrm{mM}$ MES buffer, $\mathrm{pH}$ 7; for further details see SI). Then DCPIP ${ }^{\text {ox }}$ and either $5 \mu \mathrm{M}$ $\mathrm{MnCl}_{2}$ (in A) or $240 \mu \mathrm{M} \mathrm{MnCl}_{2}$ (in B) were added, followed by continuous white-light 
bioRxiv preprint doi: https://doi.org/10.1101/2020.03.03.975516; this version posted March 5, 2020. The copyright holder for this preprint (which was not certified by peer review) is the author/funder. All rights reserved. No reuse allowed without permission.

Chernev et al, Light-driven formation of manganese oxides by photosystem II

illumination $\left(1000 \mu \mathrm{E} \mathrm{m}^{-2} \mathrm{~s}^{-1}\right)$ of the PSII suspensions and collection of spectra (one spectrum per minute; immediately prior to illumination, red lines, and after $3 \mathrm{~min}$ light, blue lines). The green and light-green lines correspond to the spectral contributions of DCPIP ${ }^{\text {ox }}$ to the dark and 3-min light spectra; the amplitude decrease at $604 \mathrm{~nm}$ represents the loss of DCPIP ${ }^{\text {ox }}$ due to its reduction by PSII (arrows). The dark-yellow dotted spectra are assignable to a Mnoxide, as verified by X-ray absorption spectroscopy (spectra obtained by weighted spectral deconvolution, see caption of Fig. S10, and scaled by a factor of 5, for clarity). Note that significant spectral changes due to Mn-oxide formation were only observed with $240 \mu \mathrm{M}$ $\mathrm{MnCl}_{2}$ (in B), but not with $5 \mu \mathrm{M} \mathrm{MnCl}_{2}$ (in A).

UV-vis spectra monitor PSII electron transfer. Optical absorption spectroscopy was employed for time-resolved tracking of PSII redox chemistry (Figs. 2-4 and S3-S9). DCPIP (2,6-dichlorphenol-indophenol) was added as an artificial electron acceptor for PSII that allows facile optical monitoring of light-driven electron flow ${ }^{39}$. Oxidized DCPIP (DCPIP ${ }^{\text {ox }}$ ) at $\mathrm{pH} \geq$ 7 shows strong absorption at $604 \mathrm{~nm}$ and its bright blue color vanishes upon reduction (Figs. 2, 3, see also Fig. S5) ${ }^{40}$. We explored the ability of DCPIP ${ }^{\text {ox }}$ to support and simultaneously probe PSII electron transfer by recording absorption spectra for increasing illumination periods. For intact PSII with a native $\mathrm{Mn}_{4} \mathrm{CaO}_{5}$ cluster, rapid and essentially complete DCPIP reduction was observed (Figs. S5, S6). Mn-depleted PSII showed a completely different electron transfer behavior (Figs. 3, 4 and S7, S9). By adding a $\mathrm{Mn}$ salt $\left(\mathrm{MnCl}_{2}\right)$, we investigated hexaquo-Mn ${ }^{2+}$ ions as an exogenous electron donor to PSII. $\mathrm{Mn}^{2+}$ in solution is completely colorless, i.e., it does not absorb in the $300-900 \mathrm{~nm}$ region. In the dark in the presence of DCPIP ${ }^{\text {ox }}$ and $\mathrm{Mn}^{2+}$ ions or upon illumination in the absence of $\mathrm{Mn}^{2+}$, we did not observe any major spectral change of the PSII suspension (aside from minor bleaching of PSII chlorophyll due to oxidative damage ${ }^{41}$ ). No absorption changes accountable to DCPIP (i.e., due to its reduction) under illumination were observed in the presence of $\mathrm{MnCl}_{2}$ with simultaneous absence of PSII (Fig. S8). These experiments verify for the Mn-depleted PSII: electron transfer towards DCPIP requires both, visible light to drive the PSII electron transfer reactions and $\mathrm{Mn}^{2+}$ ions that can serve as a donor in the light-induced electron transfer.

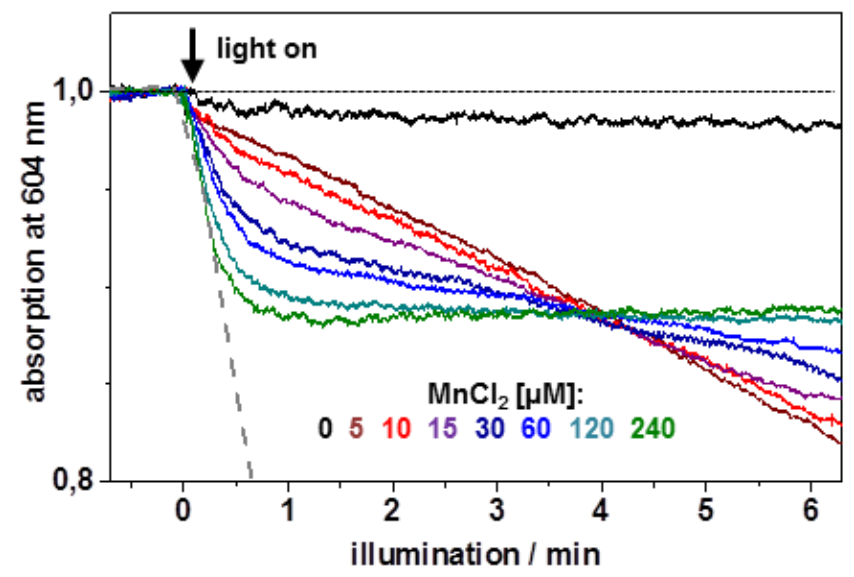

Figure 4: Kinetics of light-dependent electron flow in Mn-depleted PSII at various concentrations of solvated $\mathrm{Mn}^{2+}$ ions. The decrease in absorption at $604 \mathrm{~nm}$ monitors the light-driven reduction of the artificial electron acceptor $\left(60 \mu \mathrm{M} \mathrm{DCPIP}^{\mathrm{ox}}, \mathrm{pH} 7\right)$ due to the oxidation of $\mathrm{Mn}^{2+}$ ions by PSII. The grey dashed line illustrates the rate of DCPIP reduction by fully intact PSII under similar conditions (Fig. S6). 
Electron donation by $\mathbf{M n}^{2+}$ ions. At low $\mathrm{MnCl}_{2}$ concentration $(5 \mu \mathrm{M})$, a linear decrease in the amount of DCPIP ${ }^{\text {ox }}$ indicates a small and constant rate of electron donation at the PSII donor side (Figs. 3, 4), which is only about $8 \%$ of the level reached in intact PSII. It may be assignable to PSII centers that either acquire an alternative minor reactivity or support light-driven oxygen evolution at exceedingly low rate. This slow electron transfer is not visible at higher $\mathrm{MnCl}_{2}$ concentrations suggesting that at high $\mathrm{MnCl}_{2}$ concentrations, the PSII centers do not acquire a metal complex that supports continuous low-rate electron transfer. Therefore we consider this phenomenon, albeit of clear interest for future investigation, irrelevant for the analysis of oxide formation herein observed at higher $\mathrm{MnCl}_{2}$ concentrations. For increasing $\mathrm{MnCl}_{2}$ concentrations, a clearly more rapid phase of DCPIP ${ }^{\text {ox }}$ reduction grew in (Fig. 3, arrows; Figs. 4 and S7). Its amplitude saturated at $240 \mu \mathrm{M} \mathrm{MnCl}_{2}$ and indicates reduction of $\sim 17 \%(\sim 10 \mu \mathrm{M})$ of the initial DCPIP ${ }^{\text {ox }}(60 \mu \mathrm{M})$, which corresponds to up to 200 transferred electrons per PSII. Based on the Mn concentration dependence and the results presented in the following, we can assign this rapid DCPIP reduction phase to oxidation of $\mathrm{Mn}^{2+}$ ions and formation of high-valent $\mathrm{Mn}\left(\mathrm{III} / \mathrm{IV}\right.$ ) oxide particles. At $240 \mu \mathrm{M} \mathrm{MnCl}_{2}$, DCPIP reduction is completed after about $1 \mathrm{~min}$ of illumination likely indicating that further electron donation to the PSII donor side (and thus further DCPIP reduction) was impaired after the formation of a Mn oxide particle at the PSII donor side that blocks access of further $\mathrm{Mn}^{2+}$ ions to the oxidant, which is the tyrosine $\left(\mathrm{Y}_{\mathrm{Z}}\right)$ radical (see Fig. 1).

UV-vis spectra point towards Mn-oxide formation. To search for evidence of Mn oxide formation, informative absorption difference spectra of Mn-depleted PSII before and after illumination were calculated (Figs. 3 and S7). For $60 \mu \mathrm{M} \mathrm{MnCl}_{2}$, after completion of rapid DCPIP $^{\text {ox }}$ reduction (3 min), there was a broad absorption increase (ranging from 350-700 nm), which is similar to the wide-range absorption of Mn oxides ${ }^{25}$. For higher concentrations of $\mathrm{MnCl}_{2}$, the absorption assigned to Mn oxides gained strength and became maximal at $240 \mu \mathrm{M}$ $\mathrm{MnCl}_{2}$ (Fig. 3). Using alternative electron acceptors (Fig. S9), similar or even higher Mn-oxide amounts were detected with DCBQ (2,5-dichloro-1,4-benzoquinone) or PPBQ (phenyl-pbenzoquinone), resembling the native quinone acceptor $\left(\mathrm{Q}_{\mathrm{B}}\right)$, but the slow (hydrophilic) acceptor ferricyanide $\left(\mathrm{K}_{3} \mathrm{Fe}^{\mathrm{III}}(\mathrm{CN})_{6}\right)$ did not yield significant Mn-oxide formation.

PSII with 50-100 bound Mn ions prepared for analysis by X-ray spectroscopy. To investigate the $\mathrm{Mn}^{2+}$ oxidation products and identify their atomic structure, we employed X-ray absorption spectroscopy (XAS) at the Mn K-edge (Figs. 5 and S10, S11). Mn-depleted PSII was illuminated for 3 min with $240 \mu \mathrm{M} \mathrm{MnCl}_{2}$ and $60 \mu \mathrm{M} \mathrm{PPBQ}^{\mathrm{ox}}$ (pH 7.5), the reaction was terminated by rapid sample cooling in the dark, and the PSII membranes were pelleted by centrifugation and then transferred to XAS sample holders, followed by freezing in liquid nitrogen and later collection of X-ray spectra at $20 \mathrm{~K}$ (see SI). The metal content was determined by X-ray fluorescence analytics (Tables $1, \mathrm{~S} 1$ ), revealing $65 \pm 19 \mathrm{Mn}$ ions per initially Mndepleted PSII after illumination in the presence of $240 \mu \mathrm{M} \mathrm{MnCl}_{2}$. The calcium content in the PSII-formed Mn oxide could not be reliably determined because $\mathrm{CaCl}_{2}$ was present in the buffer and $\mathrm{Ca}$ is known to bind unspecifically to the used PSII membrane particle preparation (Table S1) ${ }^{42}$. 

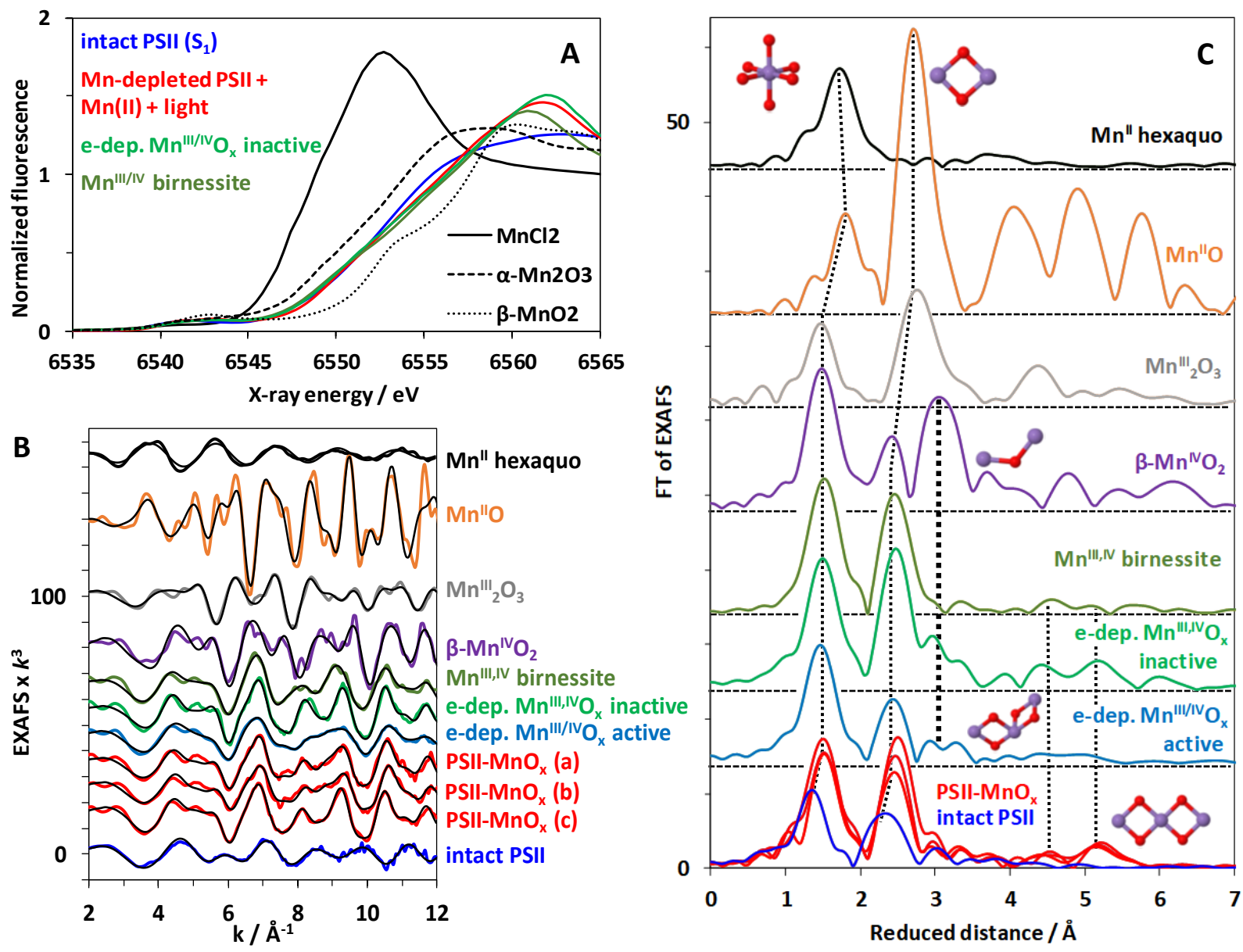

Figure 5: X-ray absorption spectroscopy evidencing PSII-bound Mn oxide of the birnessitetype. (A) XANES spectra of the native PSII with its active-site $\mathrm{Mn}(\mathrm{III})_{2} \mathrm{Mn}(\mathrm{IV})_{2} \mathrm{CaO}_{5}$ cluster (blue) and Mn-depleted PSII after light-driven formation of Mn oxide (red) are compared to the spectra of $\mathrm{Mn}^{2+}$ in solution, electrodeposited Mn-oxide (green), synthetic birnessite (dark green) and further Mn oxides (black lines). (B) The corresponding EXAFS spectra in $k$-space as in A as well as spectra of further Mn compounds. (C) Fourier-transformed (FT) EXAFS spectra (as in B) of: $\mathrm{Mn}^{2+}$ ions in solution, indicated reference Mn oxides, the $\mathrm{Mn}_{4} \mathrm{CaO}_{5}$ cluster in intact PSII, and Mn-depleted PSII after illumination in the presence of $\mathrm{Mn}^{2+}$. Structural motifs corresponding to the individual peaks are schematically shown; FT peaks relating to the same structural motif are connected by dotted lines. Mn-depleted PSII particles $\left(20 \mu \mathrm{g} \mathrm{mL}^{-1}\right.$ chlorophyll) were illuminated for $3 \mathrm{~min}\left(4000 \mu \mathrm{E} \mathrm{m}^{-2} \mathrm{~s}^{-1}\right)$ in the presence of $240 \mu \mathrm{M} \mathrm{MnCl}_{2}$ and $60 \mu \mathrm{M}$ PPBQ (Fig. S9; buffer conditions: $1 \mathrm{M}$ glycine-betaine, $15 \mathrm{mM} \mathrm{NaCl}, 5 \mathrm{mM} \mathrm{CaCl}$, $5 \mathrm{mM} \mathrm{MgCl}_{2}, 25 \mathrm{mM}$ MES buffer, $\mathrm{pH} \mathrm{8)}$ and subsequently collected by centrifugation. (The spectra shown in $\mathrm{A}$ as a red line represents the mean of the three spectra from individual samples shown in $\mathrm{B}$ and $\mathrm{C}$ as red lines as obtained after subtraction of a $5 \%$ aqueous $\mathrm{Mn}^{2+}$ contribution. See Table S2 for details and further data.)

X-ray spectroscopy reveals extended Mn(III/IV) oxides. The shape of the XANES (X-ray absorption near-edge structure) pronouncedly differed from hexaquo- $\mathrm{Mn}^{2+}$, micro-crystalline Mn oxides $\left(\mathrm{Mn}_{2}^{\mathrm{III}} \mathrm{O}_{3}, \mathrm{Mn}^{\mathrm{II}, \mathrm{III}}{ }_{3} \mathrm{O}_{4}, \beta-\mathrm{Mn}^{\mathrm{IV}} \mathrm{O}_{2}\right)$, and native PSII, but was similar to layered 
Mn(III,IV) oxides denoted as birnessite ${ }^{43-45}$ (Fig. 5A). The K-edge energy indicated a mean redox level of about +3.5 , suggesting equal amounts of $\mathrm{Mn}(\mathrm{III})$ and $\mathrm{Mn}(\mathrm{IV}$ ) ions (Figs. 5A, S10). EXAFS (extended X-ray absorption fine structure) analysis revealed the atomic structure of the PSII-bound Mn-oxide (Figs. 5B, S11; Table S2). The EXAFS of Mn-depleted PSII with bound Mn oxide closely resembled birnessite (44) in showing a similar main Mn-O bond length ( $\sim 1.90 \AA)$, minor longer Mn-O bond length contributions ( 2.30 , assignable to Jahn-Teller elongated $\mathrm{Mn}-\mathrm{O}$ distances of $\mathrm{Mn}^{\mathrm{III}}$ ions) as well as similar main and minor Mn-Mn distances ( 2.88 $⿱ ㇒ ⿻ 二 乚, ~ 3.45 \AA)$. Also, longer Mn-Mn distances ( 5.00,$\sim 5.54 \AA)$ were similar. On the other hand, the EXAFS spectra differ clearly from $\mathrm{Mn}(\mathrm{III})_{2} \mathrm{O}_{3}$ and $\beta-\mathrm{Mn}(\mathrm{IV}) \mathrm{O}_{2}$. The metrical parameters from EXAFS simulations are in good agreement with earlier data for the here studied and related Mn oxide species of the birnessite-type ${ }^{21,22,25,46,47}$. We note that the longrange order in the oxide particles produced by PSII even exceeds that of the herein used reference oxides of the birnessite-type, as indicated by the magnitudes of the Fourier peaks assignable to the 2.87 and $5.54 \AA$ distances, verifying formation of a comparably extended and well-ordered Mn oxide. Notably, according to the similar XAS spectra, a similar birnessite-type $\mathrm{Mn}(\mathrm{III}, \mathrm{IV})$-oxide was formed both in the presence and absence of $\mathrm{CaCl}_{2}$ in the illumination buffer (Fig. S12).

\section{Discussion}

Mn oxide formation by PSII. We have obtained the first direct experimental evidence that PSII devoid of $\mathrm{Mn}_{4} \mathrm{CaO}_{5}$ is capable of forming $\mathrm{Mn}$ (III,IV)-oxide particles of the birnessite type by light-driven oxidation of $\mathrm{Mn}^{2+}$ ions. Light-driven $\mathrm{Mn}^{2+}$ oxidation also can promote selfassembly of functional $\mathrm{Mn}_{4} \mathrm{CaO}_{5}$, which is a comparably inefficient (low quantum yield) lowlight process denoted as photoactivation ${ }^{19,20}$. Cheniae et al. investigated photoactivation and observed light-driven binding of about 18 membrane-bound $\mathrm{Mn}$ ions per PSII if $\mathrm{Ca}$ ions were excluded from the photoassembly buffer ${ }^{48}$, whereas we here observe binding of clearly more Mn ions (65 $\pm 19 \mathrm{Mn}$ ions, Table 1), irrespective of the absence or presence of Ca ions at moderate concentration $(5 \mathrm{mM})$ in the photoassembly buffer (Figure S12). The presence of $5 \mathrm{mM} \mathrm{CaCl}_{2}$ allows for photoactivation, although higher concentration are required for optimal photoactivation yield ${ }^{48,49}$. The about 20 times higher light intensities we used likely promoted the oxidation and binding of numerous $\mathrm{Mn}$ ions at the expense of formation of a single native $\mathrm{Mn}_{4} \mathrm{CaO}_{5}$ cluster, because the latter requires low light intensities presumably due to the presence of a slow 'dark rearrangement' step for assembly ${ }^{19}$.

Since Cheniae's work, it had remained an open question in what form a larger number of Mn ions can bind to PSII membrane particles. Coordination of individual high-valent Mn ions to protein groups is one possibility (as often observed for divalent cations and trivalent Fe ions); the formation of extended protein-bound Mn-oxides nanoparticles is another possibility. Under our high-light conditions, Mn(III,IV)-oxide formation clearly is dominant. The Mn-oxide cluster size seems to be limited to around $100 \mathrm{Mn}$ ions, which may correspond to a nanoparticle of about $20 \AA$ in diameter (Fig. 6A). Such a particle may well be adopted in the PSII cavity that becomes solvent-exposed upon removal of the extrinsic protein subunits (Fig. 1). These subunits are evolutionarily younger than the PSII core proteins ${ }^{50}$ and are absent in related anoxygenic photosystems ${ }^{51}$. Thus, it is well conceivable that an early PSII ancestor would have 
lacked these extrinsic proteins and therefore could accommodate a Mn-oxide nanoparticle. Furthermore, an ancient autotroph, capable of exploiting $\mathrm{Mn}^{2+}$ as a metabolic reductant ${ }^{32,33}$, would be expected to be configured so that the donor side of the early PSII ancestor would be exposed to the environment as opposed to being sequestered within the lumen of modern thylakoids. In this context, the cyanobacterium Gloeobacter violaceous provides an interesting example. Gloeobacter occupies a basal phylogenetic position and evolved before the appearance of thylakoids. It possesses photosynthetic reaction centers that are located in the cytoplasmic membrane with the oxidizing domain of photosystem II facing the periplasmic space and thus the exterior of the cell ${ }^{52}$. Thus Gloeobacter provides an example of how a primordial reaction center might have been arranged to facilitate the photochemical utilization of $\mathrm{Mn}^{2+}$ as a reductant source, as originally proposed by Zubay ${ }^{32}$.

Relation to water-oxidizing synthetic Mn oxides. Birnessite and buserite are layered, typically non-crystalline metal-oxides with sheets of edge-sharing $\mathrm{MnO}_{6}$ octahedra (which corresponds to di- $\mu$-oxo bridging between neighboring $\mathrm{Mn}$ ions) separated by water and cations, e.g., $\mathrm{Na}^{+}$or $\mathrm{Ca}^{2+}$, in the interlayer space ${ }^{43,44}$. Birnessite and buserite differ regarding the number of water-cation layers in between two oxide layers (one in birnessite, two in buserite), but share the same fundamental structure of the Mn(III,IV) oxide layers and thus are often jointly denoted as birnessite-type Mn oxides. Noteworthy, a Mn oxide denoted as ranciéite is isostructural to birnessite and contains $\mathrm{Mn}$ and $\mathrm{Ca}$ ions at approximately the same 4:1 stoichiometry as present in the $\mathrm{Mn}_{4} \mathrm{CaO}_{5}$ cluster of PSII ${ }^{53}$, suggesting a possible relation ${ }^{27,54-}$ 56 . Birnessite-type Mn oxides are a major component of Mn-oxide ocean nodules ${ }^{43}$ and biogenic Mn oxides ${ }^{57}$. Their diagenetic reductive conversion to Mn-bearing carbonates, on geological time scales, may explain the early Mn deposits reported by Johnson et al. ${ }^{33}$. Notably, by electrodeposition and other synthesis protocols, $\mathrm{Mn}(\mathrm{III} / \mathrm{IV})$ oxides of the birnessite type can be formed that are either active or largely inactive in water oxidation, depending on their atomic structure ${ }^{21,22,25,46,58,59}$. These $\mathrm{Mn}\left(\mathrm{III} / \mathrm{IV}\right.$ ) oxides share key features with the $\mathrm{Mn}_{4} \mathrm{CaO}_{5}$ cluster of the biological catalyst, including joint structural motifs and facile oxidation state changes during catalytic operation ${ }^{24}$. The presence of $\mathrm{Ca}$ ions is especially favorable for water oxidation activity by synthetic manganese oxides, pointing towards similar water-oxidation mechanisms in the synthetic oxides and the biological $\mathrm{Mn}_{4} \mathrm{CaO}_{5}$ cluster of PSII ${ }^{21,22,25,60}$. Regarding their high degree of structural order, the Mn oxide particles formed by PSII resemble electrodeposited Mn oxides that are able to undergo $\mathrm{Mn}(\mathrm{III})-\mathrm{Mn}(\mathrm{IV})$ redox transitions, but exhibit low electrochemical water oxidation activity ${ }^{24}$. The structural characteristics that have been identified for transforming a largely inactive Mn oxide into an oxide with sizeable wateroxidation activity ${ }^{24}$ are apparently lacking in the Mn oxide particles formed by PSII, which may explain the absence of detectable water-oxidation activity by the herein investigated PSIIbound Mn oxide particle. 
A

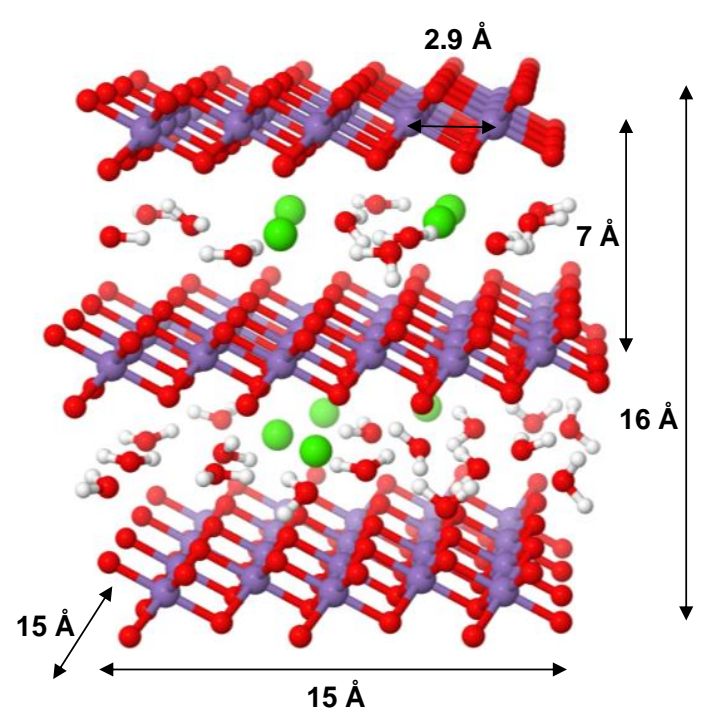

B
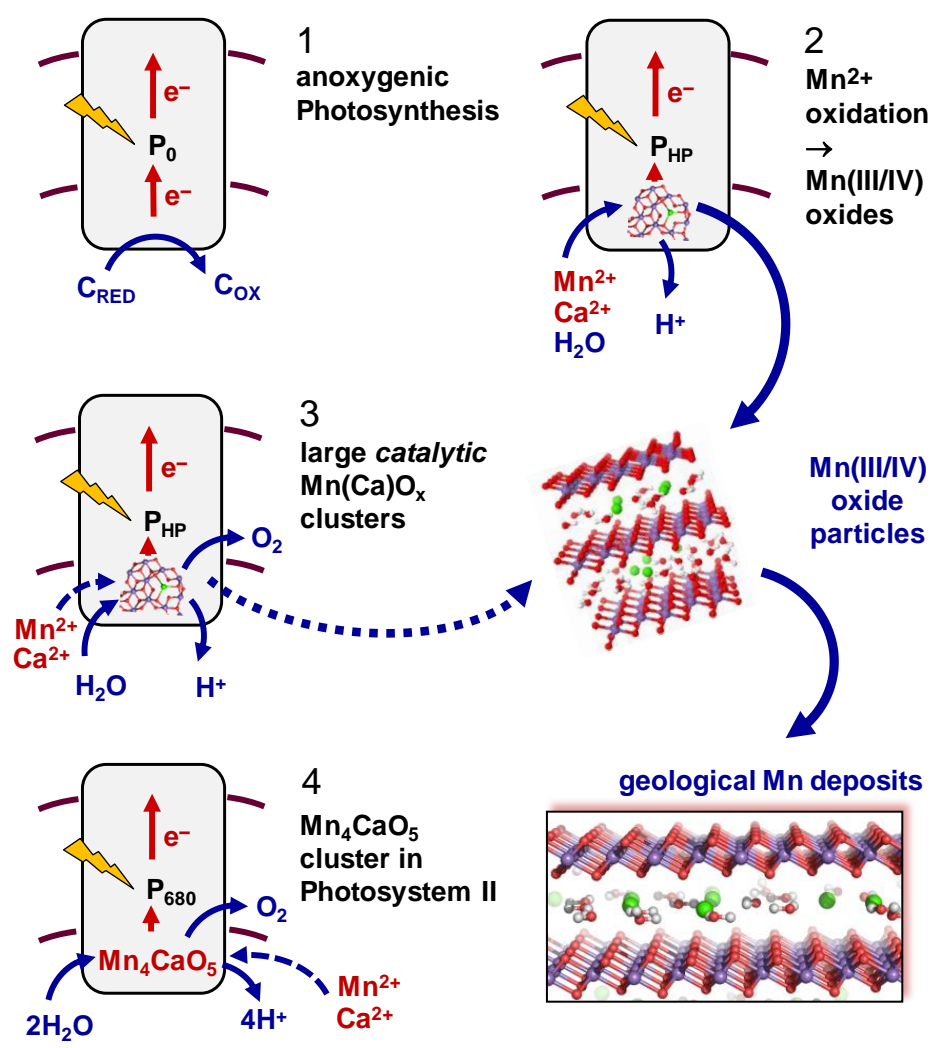

Figure 6: Evolution of oxygenic photosynthesis and relation to geological Mn-oxide deposits. (A) Structural model of a birnessite fragment with $64 \mathrm{Mn}$ ions (based on the atomic coordinates in ref. ${ }^{61}$, protons were added for illustration only). Atom color coding: violet, $\mathrm{Mn}(\mathrm{III} / \mathrm{IV})$ ions; red, O or $\mathrm{OH}$; green, $\mathrm{Ca}^{2+}$; grey, H. (B) Proposed sequence of evolutionary events. (1) Starting from an anoxygenic photosystem with a low-potential primary donor $\left(\mathrm{P}_{0}\right)$ in a marine cyanobacterial ancestor, (2) a higher donor potential $\left(\mathrm{P}_{\mathrm{HP}}\right)$ facilitated $\mathrm{Mn}^{2+}$ oxidation ${ }^{62}$ to generate protein-bound Mn(III,IV)-oxide clusters, which upon sedimentation contributed to geological Mn-oxide deposits ${ }^{33}$. (3) The PSII-bound clusters developed into primordial water-oxidizing and $\mathrm{O}_{2}$-evolving catalytic complexes, which, (4) due to a dedicated binding site, were down-sized to the present $\mathrm{Mn}_{4} \mathrm{CaO}_{5}$ catalyst. 
Mechanism of Mn-oxide formation. The basic biochemical mechanism of the here described light-induced Mn-oxide formation likely involves initial binding of $\mathrm{Mn}^{2+}$ ions followed by $\mathrm{Mn}$ oxidation and stabilization of the oxidized Mn(III/IV) ions by di- $\mu$-oxo bridging, in analogy to both the photoassembly process of today's $\mathrm{Mn}_{4} \mathrm{CaO}_{5}$ cluster ${ }^{19,20}$ and the "oxidative selfassembly" process in electrodeposition of non-biological birnessite-type Mn oxides ${ }^{25,46}$. The formation of extended oxide particles likely involves a nucleation-and-growth mechanism. In the photosystem, the initial site of $\mathrm{Mn}^{2+}$ binding and formation of an oxide nucleus likely is provided by carboxylate and possibly imidazole sidechains of protein residues followed by an oxide growth that does not require further ligating residues.

Oxide-incorporation hypothesis on the evolution of today's $\mathrm{Mn}_{4} \mathrm{CaO}_{5}$ cluster. Various hypotheses on the origin of the $\mathrm{Mn}_{4} \mathrm{CaO}_{5}$ cluster have been proposed. According to Raymond and Blankenship the interaction of an anoxygenic PSII with a manganese catalase, utilizing hydrogen peroxide as the source of electrons, led to the formation of today's $\mathrm{Mn}_{4} \mathrm{CaO}_{5}$ cluster 28, without invoking Mn oxides. Dismukes and coworkers developed hypotheses on the evolution of oxygenic photosynthesis by focusing on the inorganic chemistry of $\mathrm{Mn}$ and bicarbonate ${ }^{63}$; their analyses could complement the herein developed ideas on the evolutionary role of Mn oxides in the future. In 2001, Russell and Hall developed their influential Mn-oxide incorporation hypothesis ${ }^{54}$. They suggested ".. that a "ready-made" cluster must have been coopted whole by a (mutant?) protein .." ${ }^{55,56}$. Russell and Hall specifically proposed that dissolved $\mathrm{Mn}^{2+}$ ions were photo-oxidized at extremely short wavelengths ${ }^{64}$ to colloidal clusters of $\left[\mathrm{CaMn}_{4} \mathrm{O}_{9} \cdot 3 \mathrm{H}_{2} \mathrm{O}\right]$, which are closely related to the birnessite-type $\mathrm{Mn}$ oxide denoted as rancicéite. Incorporation of this or a similar "ready-made" $\mathrm{Mn}_{4} \mathrm{Ca}$ species into a PSII ancestor would have led to the $\mathrm{Mn}_{4} \mathrm{CaO}_{5}$ cluster of today's PSII. This hypothesis is in line with analyses of Yachandra and Sauer who systematically compared the structural relations between various $\mathrm{Mn}$ oxides and the biological metal complex, revealing intriguing similarities ${ }^{27}$ (for further discussion, see SI Appendix - background text).

Alternative hypothesis on evolution of the $\mathrm{Mn}_{4} \mathrm{CaO}_{5}$ cluster. We see a close relation between inorganic $\mathrm{Mn}$ oxides and today's $\mathrm{Mn}_{4} \mathrm{CaO}_{5}$ cluster of PSII that differs distinctively from the Mn-oxide incorporation hypotheses outlined above. In our study, facile formation of birnessite-type Mn oxide particles by PSII is reported. They (i) share structural motifs with the biological cluster in PSII ${ }^{10,65}$ and biogenic Mn oxides in general ${ }^{57,66}$ and (ii) resemble synthetic $\mathrm{Mn}$ oxides closely that have been investigated as synthetic catalyst materials ${ }^{24}$. On these grounds we propose a scenario illustrated in Figure 6: Rather than Mn oxide incorporation, Mn oxide nanoparticles were formed by an evolutionary precursor of PSII, inter alia enabling the formation of early geological $\mathrm{Mn}$ oxide deposits. Initially, dissolved $\mathrm{Mn}^{2+}$ ions served as a source of reducing equivalents eventually needed for $\mathrm{CO}_{2}$ reduction, as has been suggested first by Zubay ${ }^{32}$ and later by others ${ }^{31,33}$. At a later stage, down-sized oxide particles developed into today's water-oxidizing $\mathrm{Mn}_{4} \mathrm{CaO}_{5}$ cluster. Are there evolutionary relicts that may support the above hypothesis? Extensive studies on the diversity of the PSII reaction center protein D1 have revealed several atypical variants that can be distinguished phylogenetically ${ }^{67,68}$. These early evolved forms lack many residues needed for the binding of today's $\mathrm{Mn}_{4} \mathrm{CaO}_{5}$ cluster and could relate to ancient Mn oxide forming photosystems, even though today they might play other physiological roles (e.g., in the synthesis of chlorophyll $f^{69}$ ). 
Summary of potential evolutionary implications. The ability for light-driven Mn oxide formation by an ancient photosystem represents an important touchstone for evaluation of three interrelated hypotheses that each addresses a remarkable facet of the evolution of the Earth's biosphere and geosphere:

(i) The ability for direct and facile photosynthetic formation of stable Mn(III/IV)-oxide particles supports that early Mn deposits ${ }^{33}$ resulted directly from photosynthetic activity.

(ii) Structural and functional similarities between water-oxidizing synthetic Mn oxides and the here described Mn-oxide formation by PSII suggests that in the evolution of PSII, there may have been a transition from extended $\mathrm{Mn}$-oxide nanoparticles towards the $\mathrm{Mn}_{4} \mathrm{CaO}_{5}$ cluster of today's PSII, as illustrated by Figure 6 .

(iii) An early quasi-respiratory cycle has been proposed that involves formation of $\mathrm{Mn}(\mathrm{III} / \mathrm{IV}$ ) oxide particles followed by utilization of the oxidizing equivalents stored in the $\mathrm{Mn}$ oxide for an efficient quasi-respiratory activity in the Archean or early Paleoproterozoic, when the Earth's atmosphere had been essentially $\mathrm{O}_{2}$-free, as detailed in ${ }^{66}$.

By showing that today's PSII can form birnessite-type Mn-oxide particles efficiently, even without any specific protein subunits that would support Mn-oxide formation, the general biochemical feasibility is verified. This finding renders it highly likely that similarly also an ancient photosystem, the PSII ancestor, had the ability for light-driven formation of Mn-oxides from hexaquo $\mathrm{Mn}^{2+}$ ions. In conclusion, we believe that our successful demonstration of photosynthetic formation of $\mathrm{Mn}$ (III/IV)-oxide particles provides relevant support for the above three hypotheses.

\section{Methods}

Preparation of PSII membrane particles. Native PSII-enriched thylakoid membrane particles were prepared from fresh market spinach following our established procedures ${ }^{35}$. Their typical $\mathrm{O}_{2}$-evolution activity (as determined by polarography with a Clark-type electrode at $27^{\circ} \mathrm{C}$ ) was $\sim 1200 \mu \mathrm{mol} \mathrm{O} \mathrm{mg}^{-1}$ chlorophyll $\mathrm{h}^{-1}$, which proved the full integrity of the PSII proteins and the water-oxidizing $\mathrm{Mn}_{4} \mathrm{CaO}_{5}$ complex. We have shown earlier that this type of PSII preparation contains $\sim 200$ chlorophyll molecules per PSII reaction center ${ }^{70,71}$. When kept for prolonged time periods in the dark, the $\mathrm{Mn}_{4} \mathrm{CaO}_{5}$ complex is synchronized in the $\mathrm{S}_{1}$ state of its catalytic cycle, which is established to represent a $\mathrm{Mn}(\mathrm{III})_{2} \mathrm{Mn}(\mathrm{IV})_{2}$ oxidation state ${ }^{72,73}$.

Mn-depletion of PSII. Removal of $\mathrm{Mn}_{4} \mathrm{CaO}_{5}$ and of the three extrinsic proteins of PSII $(18,24,33 \mathrm{kDa})$ was carried out using a literature procedure and evaluated using metal quantification and gel electrophoresis (see below) ${ }^{36}$. PSII membranes were dissolved at $200 \mu \mathrm{g}$ chlorophyll $\mathrm{mL}^{-1}$ in a high-salt buffer $(30 \mathrm{~mL})$ containing $20 \mathrm{mM}$ TEMED (N,N,N',N'tetramethylethylenediamine) as a reductant for the PSII-bound Mn(III,IV) ions, $20 \mathrm{mM}$ MES (2-(N-morpholino)ethane-sulfonic-acid) buffer ( $\mathrm{pH} 6.5$ ), and a high salt concentration ( $500 \mathrm{mM}$ $\mathrm{MgCl}_{2}$ ) and incubated in the dark on ice for $10 \mathrm{~min}$. PSII membranes were pelleted by centrifugation (Sorvall RC26, $12 \mathrm{~min}, 50000 \mathrm{~g}, 4{ }^{\circ} \mathrm{C}$ ), the pellet was 3-times washed by dissolution in a buffer $(30 \mathrm{~mL})$ containing $35 \mathrm{mM} \mathrm{NaCl}$ and $20 \mathrm{mM}$ TRIS (tris(hydroxymethyl)aminomethane) buffer ( $\mathrm{pH} 9.0$ ) and pelleting by centrifugation as above, and the final pellet of Mn-depleted PSII membranes was dissolved at $\sim 1 \mathrm{mg}$ chlorophyll $\mathrm{mL}^{-1}$ in a buffer containing $1 \mathrm{M}$ glycine-betaine, $15 \mathrm{mM} \mathrm{NaCl}, 5 \mathrm{mM} \mathrm{CaCl}_{2}, 5 \mathrm{mM} \mathrm{MgCl}_{2}$, and 
$25 \mathrm{mM}$ MES buffer (pH 6.3). The PSII preparations ( $2 \mathrm{mg}$ chlorophyll $\mathrm{mL}^{-1}$ ) were thoroughly homogenized by gentle brushing and frozen in liquid nitrogen for the spectroscopic experiments. The Mn-depleted PSII showed zero $\mathrm{O}_{2}$-evolution activity as revealed by polarography.

Total reflection X-ray fluorescence (TXRF) analysis. X-ray emission spectra were recorded on a Picofox instrument (Bruker) and metal contents of PSII samples were determined from the data using the (fit) routines available with the spectrometer ${ }^{74}$. PSII membranes were adjusted to a chlorophyll concentration of 1-2 $\mathrm{mM}$ and to a $20 \mu \mathrm{L}$ aliquot, a gallium concentration standard (1 mg mL $\mathrm{mL}^{-1}, 20 \mu \mathrm{L}$; Sigma-Aldrich) was added, and samples were homogenized by brief sonication (see Fig. S1). A $5 \mu \mathrm{L}$ aliquot of the samples was pipetted on clean quartz discs for TXRF, dried on a heating plate, loaded into the spectrometer, and TXRF spectra were recorded within 10-30 min. At least 3 repetitions of each sample and 3 independently prepared samples of each PSII preparation were analyzed.

Optical absorption spectroscopy and illumination procedures. For the optical absorption spectroscopy experiments, stock suspensions of the PSII preparations were diluted at $20 \mu \mathrm{g}$ chlorophyll $\mathrm{mL}^{-1}(\sim 0.1 \mu \mathrm{M}$ PSII centers) in a buffer $(3 \mathrm{~mL})$ containing $1 \mathrm{M}$ glycinebetaine, $15 \mathrm{mM} \mathrm{NaCl}, 5 \mathrm{mM} \mathrm{CaCl}_{2}, 5 \mathrm{mM} \mathrm{MgCl}_{2}$, and $25 \mathrm{mM} \mathrm{MES} \mathrm{buffer} \mathrm{(pH} \mathrm{6.3-8.5)} \mathrm{and}$ reactants (oxidized 2,6-dichlorophenol-indophenol $=$ DCPIP $^{\text {ox }}$ from Fluka, other electron acceptors as in Fig. S9, $\mathrm{MnCl}_{2}$ ) were added at indicated concentrations. Optical absorption spectra of the samples in a $300-900 \mathrm{~nm}$ range were recorded within about $10 \mathrm{~s}$ at given time intervals (about 0.3-1.0 min) in a $3 \mathrm{~mL}$ quartz cuvette (Helma QS1000, $1 \mathrm{~cm}$ pathlength) using a Cary 60 spectrometer (Agilent). Alternatively, time traces of absorption were recorded at selected wavelengths (i.e. $604 \mathrm{~nm}$ to monitor DCPIP ${ }^{\text {ox }}$ reduction) for up to $30 \mathrm{~min}$. Temperature logging revealed that the sample temperature varied by $<2{ }^{\circ} \mathrm{C}$ within the extended illumination periods. PSII-sample filled cuvettes in the spectrometer were continuously illuminated from the top side using a white-light lamp (Walz KL1500) with attenuation option, which was directed through a heat-protection filter (Schott KG5, ca. 400-700 nm transmission) to the cuvette by a $\sim 20 \mathrm{~cm}$ light-guide (the full cuvette volume was homogenously illuminated). Several spectra (or time points) were recorded in the dark (prior to and after addition of, e.g., DCPIP), the light was switched on (or off) at indicated time points, and data were recorded on a PC linked to the spectrometer. Evaluation and fit analysis of absorption data was carried out using the Origin software (OriginLab). Light intensities at the sample center position were determined using a calibrated sensor device inserted in the spectrometer.

$X$-ray absorption spectroscopy. XAS at the Mn K-edge was performed at beamline KMC-3 at the BESSY-II synchrotron (Helmholtz Zentrum Berlin) with the storage ring operated in top-up mode (250 mA), using a standard set-up as previously described ${ }^{25,75}$. A double-crystal $\mathrm{Si}[111]$ monochromator was used for energy scanning, the sample X-ray fluorescence was monitored with an energy-resolving 13-element germanium detector (Canberra), and samples were held in a liquid-helium cryostat (Oxford) at $20 \mathrm{~K}$ (in a 0.2 bar He heat-exchange gas atmosphere at an angle of $55^{\circ}$ to the incident X-ray beam). The X-ray spot size on the sample was shaped by slits to about 1 (vertical) x 5 (horizontal) $\mathrm{mm}^{2}$, the X-ray flux was $\sim 10^{10}$ photons $\mathrm{s}^{-1}$, the EXAFS scan duration was $\sim 30 \mathrm{~min}$. The energy axis was calibrated $( \pm 0.1 \mathrm{eV}$ accuracy) using a Gaussian fit to the pre-edge peak $(6543.3 \mathrm{eV})$ in the transmission 
spectrum of a permanganate $\left(\mathrm{KMnO}_{4}\right)$ powder sample, which was measured in parallel to the PSII samples. For XAS data evaluation, up to 30 deadtime-corrected, energy-calibrated $\left(\mathrm{I} / \mathrm{I}_{0}\right)$ XAS monochromator scans (each on a fresh sample spot) were averaged and normalized XANES and EXAFS spectra were extracted after background subtraction as previously described using in-house software ${ }^{76}$. EXAFS simulations in $k$-space were carried out using inhouse software (SimX) and scattering phase functions calculated with FEFF9.0 ${ }^{77}\left(\mathrm{~S}_{0}{ }^{2}=0.8\right)$. Calculation of the filtered $R$-factor $\left(R_{\mathrm{F}}\right.$, difference in $\%$ between fit curve and Fourierbacktransform of the experimental data in a 1-5 $\AA$ region of reduced distance) ${ }^{78}$ facilitated evaluation of the EXAFS fit quality. Fourier-transforms of EXAFS spectra were calculated with cos windows extending over $10 \%$ of both $k$-range ends.

Sample preparation for XAS. Powder samples of manganese reference compounds (Mn oxides) were prepared from commercially available chemicals $\left(\mathrm{MnCl}_{2}, \mathrm{Mn}\right.$ oxides) or from material (buserite, birnessite) that was kindly provided by the group of P. Kurz (Uni. Freiburg, Germany), diluted by grinding with boron-nitride (BN) to a level, which resulted in $<15 \%$ absorption at the K-edge maximum to avoid flattening effects in fluorescence-detected XAS spectra, loaded into Kapton-covered acrylic-glass holders, and frozen in liquid nitrogen. Aqueous $\mathrm{MnCl}_{2}(20 \mathrm{mM})$ samples were prepared at $\mathrm{pH}$ 7.0. Unless otherwise specified, PSII samples were prepared as follows: Mn-depleted PSII samples $(3 \mathrm{~mL})$ were prepared similar to the samples for optical absorption spectroscopy (see above), the $\mathrm{pH}$ was adjusted to the desired value, and samples were illuminated for $3 \mathrm{~min}$ at $1000 \mu \mathrm{E} \mathrm{m}^{-2} \mathrm{~s}^{-1}$ or kept in the dark as a control after addition of $240 \mu \mathrm{M} \mathrm{MnCl}_{2}$ and $60 \mu \mathrm{M} \mathrm{PPBQ}^{\mathrm{ox}}(\mathrm{pH}$ 7.5). Thereafter, the cuvette volume was rapidly mixed with ice-cold MES buffer ( $7 \mathrm{~mL}, \mathrm{pH} 7.5$, see above for ingredients) on ice in the dark, the $\mathrm{pH}$ was measured using a $\mathrm{pH}$ electrode and, if necessary, readjusted to the desired value (+/-0.1 pH units), the PSII membranes were pelleted by centrifugation (10 min, $20000 \mathrm{~g}, 2{ }^{\circ} \mathrm{C}$ ), and kept on ice. Several of these sample types were rapidly merged on ice in the dark by loading $(\sim 30 \mu \mathrm{L})$ into XAS holders, which were immediately frozen in liquid nitrogen. Native PSII samples were prepared by pelleting of dark-adapted $\mathrm{O}_{2}$-evolving PSII membrane particles ( $\sim 8 \mathrm{mg}$ chlorophyll $\mathrm{mL}^{-1}, \mathrm{pH} 6.3$ ), loading of the pellet material into XAS holders, and freezing in liquid nitrogen ${ }^{73}$. The shown XAS data for the electrodeposited Mn oxides has been collected in the context of earlier studies (16-18) and replotted.

\section{Data availability}

All data needed to support the conclusions of this manuscript are included in the main text and SI Appendix.

\section{Competing Interests}

The authors declare no competing interests.

\section{Author contributions}

H.D. designed the study. P.C., S.F., J.H., N.O., and D.J.N. performed the experiments. P.C., M.H., and I.Z. analyzed the data. R.L.B., D.J.N., M.H., and H.D. wrote the manuscript. 
bioRxiv preprint doi: https://doi.org/10.1101/2020.03.03.975516; this version posted March 5, 2020. The copyright holder for this preprint (which was not certified by peer review) is the author/funder. All rights reserved. No reuse allowed without permission.

Chernev et al, Light-driven formation of manganese oxides by photosystem II

\section{Acknowledgements}

We thank I. Zizak, G. Schuck, and colleagues (Helmholtz Zentrum Berlin) for technical support in the X-ray experiments at the BESSY synchrotron. We thank P. Kurz (Universität Freiburg) for providing samples of birnessite and buserite. Financial support by the Deutsche Forschungsgemeinschaft (DFG) within SFB 1078 (project A4) and by the Einstein Foundation (Berlin, Einstein Fellow project awarded to R. Burnap) is gratefully acknowledged. Moreover, this study has been funded by the Deutsche Forschungsgemeinschaft (DFG, German Research Foundation) under Germany's Excellence Strategy - EXC 2008/1 - 390540038 (Gefördert durch die Deutsche Forschungsgemeinschaft (DFG) im Rahmen der Exzellenzstrategie des Bundes und der Länder - EXC 2008/1 - 390540038).

\section{References}

1 Rosing, M. T. \& Frei, R. U-rich Archaean sea-floor sediments from Greenland - indications of > 3700 Ma oxygenic photosynthesis. Earth Planet. Sci. Lett. 217, 237-244 (2004).

2 Fischer, W. W., Hemp, J. \& Johnson, J. E. Manganese and the evolution of photosynthesis. Orig. Life Evol. Biosph. 45, 351-357 (2015).

3 Anbar, A. D., Till, C. B. \& Hannah, M. A. Bridge the planetary divide. Nature 539, 25-27 (2016).

4 McEvoy, J. P. \& Brudvig, G. W. Water-splitting chemistry of photosystem II. Chem. Rev. 106, 4455-4483 (2006).

5 Dau, H. \& Haumann, M. The manganese complex of photosystem II in its reaction cyclebasic framework and possible realization at the atomic level. Coord. Chem. Rev. 252, 273-295 (2008).

6 Cox, N. \& Messinger, J. Reflections on substrate water and dioxygen formation. Biochim. Biophys. Acta 1827, 1020-1030 (2013).

7 Perez-Navarro, M., Neese, F., Lubitz, W., Pantazis, D. A. \& Cox, N. Recent developments in biological water oxidation. Curr. Opin. Chem. Biol. 31, 113-119 (2016).

8 Barber, J. Photosynthetic water splitting by the $\mathrm{Mn}_{4} \mathrm{Ca}^{2+} \mathrm{O}_{\mathrm{x}}$ catalyst of photosystem II: its structure, robustness and mechanism. Quarterly reviews of biophysics 50, e13 (2017).

9 Nowicka, B. \& Kruk, J. Powered by light: Phototrophy and photosynthesis in prokaryotes and its evolution. Microbiol. Res. 186, 99-118 (2016).

10 Shen, J. R. The structure of photosystem II and the mechanism of water oxidation in photosynthesis. Annu. Rev. Plant Biol. 66, 23-48 (2015).

$11 \mathrm{Su}, \mathrm{X}$. D. et al. Structure and assembly mechanism of plant $\mathrm{C}_{2} \mathrm{~S}_{2} \mathrm{M}_{2}$-type PSII-LHCII supercomplex. Science 357, 816-820 (2017).

12 Dau, H., Zaharieva, I. \& Haumann, M. Recent developments in research on water oxidation by photosystem II. Curr. Opin. Chem. Biol. 16, 3-10 (2012).

13 Nelson, N. \& Junge, W. Structure and energy transfer in photosystems of oxygenic photosynthesis. Annu. Rev. Biochem. 84, 659-683 (2015).

14 Vinyard, D. J. \& Brudvig, G. W. Progress toward a molecular mechanism of water oxidation in photosystem II. Annu. Rev. Phys. Chem. 68, 101-116 (2017).

15 Dau, H. \& Haumann, M. Eight steps preceding O-O bond formation in oxygenic photosynthesis - a basic reaction cycle of the photosystem II manganese complex. Biochim. Biophys. Acta 1767, 472-483 (2007).

16 Barber, J. Photosynthetic energy conversion: natural and artificial. Chem. Soc. Rev. 38, 185196 (2009).

17 Dau, H. et al. The mechanism of water oxidation: from electrolysis via homogeneous to biological catalysis. Chem CatChem 2, 724-761 (2010). 
bioRxiv preprint doi: https://doi.org/10.1101/2020.03.03.975516; this version posted March 5, 2020. The copyright holder for this preprint (which was not certified by peer review) is the author/funder. All rights reserved. No reuse allowed without permission.

Chernev et al, Light-driven formation of manganese oxides by photosystem II

Li, J. et al. Frontiers of water oxidation: the quest for true catalysts. Chem. Soc. Rev. 46, 61246147 (2017).

19 Bao, H. \& Burnap, R. L. Photoactivation: The light-driven assembly of the water oxidation complex of photosystem II. Front. Plant Sci. 7 (2016).

20 Dasgupta, J., Ananyev, G. M. \& Dismukes, G. C. Photoassembly of the water-oxidizing complex in photosystem II. Coord. Chem. Rev. 252, 347-360 (2008).

21 Zaharieva, l. et al. Synthetic manganese-calcium oxides mimic the water-oxidizing complex of photosynthesis functionally and structurally. Energy Environ. Sci. 4, 2400-2408 (2011).

22 Wiechen, M., Zaharieva, I., Dau, H. \& Kurz, P. Layered manganese oxides for water-oxidation: alkaline earth cations influence catalytic activity in a photosystem Il-like fashion. Chem. Sci. 3, 2330-2339 (2012).

23 Kurz, P. Biomimetic water-oxidation catalysts: manganese oxides. Sol. Energy 371, 49-72 (2016).

24 Zaharieva, l. et al. Water oxidation catalysis - role of redox and structural dynamics in biological photosynthesis and inorganic manganese oxides. Energy Environ. Sci. 9, 2433-2443 (2016).

25 González-Flores, D. et al. Electrosynthesis of biomimetic manganese-calcium oxides for water oxidation catalysis - atomic structure and functionality. ChemSusChem 9, 379-387 (2016).

26 Blankenship, R. E. \& Hartman, H. The origin and evolution of oxygenic photosynthesis. Trends Biochem. Sci. 23, 94-97 (1998).

27 Sauer, K. \& Yachandra, V. K. A possible evolutionary origin for the $\mathrm{Mn}_{4}$ cluster of the photosynthetic water oxidation complex from natural $\mathrm{MnO}_{2}$ precipitates in the early ocean. Proc. Natl. Acad. Sci. U.S.A 99, 8631-8636 (2002).

28 Raymond, J. \& Blankenship, R. The origin of the oxygen-evolving complex. Coord. Chem. Rev. 252, 377-383 (2008).

29 Khorobrykh, A. et al. Evolutionary origins of the photosynthetic water oxidation cluster: bicarbonate permits $\mathrm{Mn}(2+)$ photo-oxidation by anoxygenic bacterial reaction centers. Chembiochem 14, 1725-1731 (2013).

30 Cardona, T. Reconstructing the origin of oxygenic photosynthesis: do assembly and photoactivation recapitulate evolution? Front. Plant Sci. 7 (2016).

31 Martin, W. F., Bryant, D. A. \& Beatty, J. T. A physiological perspective on the origin and evolution of photosynthesis. FEMS Microbiol. Rev. 42, 205-231 (2018).

32 Zubay, G. Origins of Life on Earth and in the Cosmos. 2 edn, (Academic Press, Cambridge, 2000).

33 Johnson, J. E. et al. Manganese-oxidizing photosynthesis before the rise of cyanobacteria. Proc. Natl. Acad. Sci. U.S.A 110, 11238-11243 (2013).

34 Zhang, M. et al. Structural insights into the light-driven auto-assembly process of the water oxidizing $\mathrm{Mn}_{4} \mathrm{CaO}_{5}$-cluster in photosystem II. Elife 6, e26933 (2017).

35 Schiller, H. \& Dau, H. Preparation protocols for high-activity photosystem II membrane particles of green algae and higher plants, $\mathrm{pH}$ dependence of oxygen evolution and comparison of the $\mathrm{S}_{2}$-state multiline signal by X-band EPR spectroscopy. J. Photochem. Photobiol. B 55, 138-144 (2000).

36 Allakhverdiev, S. I. et al. Reconstitution of the water-oxidizing complex in manganesedepleted photosystem II complexes by using synthetic binuclear manganese complexes. Biochemistry 33, 12210-12214 (1994).

37 Bricker, T. M., Roose, J. L., Fagerlund, R. D., Frankel, L. K. \& Eaton-Rye, J. J. The extrinsic proteins of photosystem II. Biochim. Biophys. Acta 1817, 121-142 (2012).

38 Roose, J. L., Frankel, L. K., Mummadisetti, M. P. \& Bricker, T. M. The extrinsic proteins of photosystem II: update. Planta 243, 889-908 (2016).

39 Vernon, L. P. \& Shaw, E. R. Photoreduction of 2,6-dichlorophenolindophenol by diphenylcarbazide: a photosystem 2 reaction catalyzed by tris-washed chloroplasts and subchloroplast fragments. Plant Physiol. 44, 1645-1649 (1969). 
bioRxiv preprint doi: https://doi.org/10.1101/2020.03.03.975516; this version posted March 5, 2020. The copyright holder for this preprint (which was not certified by peer review) is the author/funder. All rights reserved. No reuse allowed without permission.

Chernev et al, Light-driven formation of manganese oxides by photosystem II

Eross, K., Svehla, G. \& Erdey, L. Use of 2,6-dichlorophenolindophenol as indicator in acid-base titrations. Anal. Chim. Acta 31, 246-\& (1964).

41 Velitchkova, M. Y. \& Picorel, R. Photobleaching of photosynthetic pigments in spinach thylakoid membranes. Effect of temperature, oxygen and DCMU. Biophys. Chem. 107, 25-32 (2004).

42 Müller, C., Liebisch, P., Barra, M., Dau, H. \& Haumann, M. The location of calcium in the manganese complex of oxygenic photosynthesis studied by X-ray absorption spectroscopy at the Ca K-edge. Phys. Scr. T115, 847-850 (2005).

43 Post, J. E. Manganese oxide minerals: Crystal structures and economic and environmental significance. Proc. Natl. Acad. Sci. U.S.A 96, 3447-3454 (1999).

44 Suib, S. L. Porous manganese oxide octahedral molecular sieves and octahedral layered materials. Acc. Chem. Res. 41, 479-487 (2008).

Lee, S. Y. et al. Screen-printed calcium-birnessite electrodes for water oxidation at neutral pH and an "Electrochemical Harriman series". ChemSusChem 7, 3442-3451 (2014).

46 Zaharieva, I. et al. Electrosynthesis, functional and structural characterization of a wateroxidizing manganese oxide. Energy Environ. Sci. 5, 7081-7089 (2012).

47 Mattioli, G., Zaharieva, I., Dau, H. \& Guidoni, L. Atomistic texture of amorphous manganese oxides for electrochemical water splitting revealed by $a b$ initio calculations combined with $X$ ray spectroscopy. J. Am. Chem. Soc. 137, 10254-10267 (2015).

48 Chen, C., Kazimir, J. \& Cheniae, G. M. Calcium modulates the photo-assembly of photosystem II (Mn) ${ }_{4}$-clusters by preventing ligation of nonfunctional high-valency states of manganese. Biochemistry 34, 13511-13526 (1995).

49 Vinyard, D. J. et al. Photosystem II oxygen-evolving complex photoassembly displays an inverse $\mathrm{H} / \mathrm{D}$ solvent isotope effect under chloride-limiting conditions. Proc. Natl. Acad. Sci. U.S.A 116, 18917-18922 (2019).

50 Ifuku, K. Localization and functional characterization of the extrinsic subunits of photosystem II: an update. Biosci. Biotechnol. Biochem. 79, 1223-1231 (2015).

51 Niederman, R. A. Development and dynamics of the photosynthetic apparatus in purple phototrophic bacteria. Biochim. Biophys. Acta 1857, 232-246 (2016).

52 Rexroth, S. et al. The plasma membrane of the cyanobacterium Gloeobacter violaceus contains segregated bioenergetic domains. Plant Cell 23, 2379-2390 (2011).

53 Ertl, A. et al. Rancieite crystals from Friesach, Carinthia, Austria. Eur. J. Mineral. 17, 163-172 (2005).

54 Russell, M. J. \& Hall, A. J. in Sixth International Conference on Carbon Dioxide Utilization. 49.

55 Russell, M. J. \& Hall, A. J. From geochemistry to biochemistry: Chemiosmotic coupling and transition element clusters in the onset of life and photosynthesis. Geochemical News 113, 612 (2002).

56 Russell, M. J., Hall, A. J. \& Mellersh, A. R. in Natural and Laboratory-Simulated Thermal Geochemical Processes 325-388 (Springer Netherlands, Dordrecht, 2003).

57 Tebo, B. M. et al. Biogenic manganese oxides: properties and mechanisms of formation. Annu. Rev. Earth Planet. Sci. 32, 287-328 (2004).

58 Bergmann, A., Zaharieva, I., Dau, H. \& Strasser, P. Electrochemical water splitting by layered and 3D cross-linked manganese oxides: correlating structural motifs and catalytic activity. Energy Environ. Sci. 6, 2745-2755 (2013).

59 Iyer, A. et al. Water oxidation catalysis using amorphous manganese oxides, octahedral molecular sieves (OMS-2), and octahedral layered (OL-1) manganese oxide structures. J. Phys. Chem. C 116, 6474-6483 (2012).

60 Frey, C. E., Wiechen, M. \& Kurz, P. Water-oxidation catalysis by synthetic manganese oxides systematic variations of the calcium birnessite theme. Dalton Trans. 43, 4370-4379 (2014).

61 Post, J. E. \& Veblen, D. R. Crystal structure determinations of synthetic sodium, magnesium, and potassium birnessite using TEM and the Rietveld method. Am. Mineral. 75, 477-489 (1990). 
bioRxiv preprint doi: https://doi.org/10.1101/2020.03.03.975516; this version posted March 5, 2020. The copyright holder for this preprint (which was not certified by peer review) is the author/funder. All rights reserved. No reuse allowed without permission.

Chernev et al, Light-driven formation of manganese oxides by photosystem II

Allen, J. F. \& Nield, J. Redox Tuning in Photosystem II. Trends Plant Sci. 22, 97-99 (2017). Dismukes, G. C. et al. The origin of atmospheric oxygen on Earth the innovation of oxygenic photosynthesis. Proc. Natl. Acad. Sci. U.S.A 98, 2170-2175 (2001).

64 Anbar, A. D. \& Holland, H. D. The photochemistry of manganese and the origin of Banded Iron Formations. Geochim. Cosmochim. Acta 56, 2595-2603 (1992).

65 Kern, J. et al. Structures of the intermediates of Kok's photosynthetic water oxidation clock. Nature 563, 421-425 (2018).

66 Dau, H., Nürnberg, D. J. \& Burnap, R. L. in Bioenergetics: Oxygen Production and Reduction 367-396 (World Scientific Publishers, Singapore, 2019).

67 Cardona, T., Murray, J. W. \& Rutherford, A. W. Origin and evolution of water oxidation before the last common ancestor of the cyanobacteria. Mol. Biol. Evol. 32, 1310-1328 (2015). Murray, J. W. Sequence variation at the oxygen-evolving centre of photosystem II: a new class of 'rogue' cyanobacterial D1 proteins. Photosynth. Res. 110, 177-184 (2012). Ho, M. Y., Shen, G., Canniffe, D. P., Zhao, C. \& Bryant, D. A. Light-dependent chlorophyll $f$ synthase is a highly divergent paralog of PsbA of photosystem II. Science 353 (2016). Barra, M., Haumann, M. \& Dau, H. Specific loss of the extrinsic $18 \mathrm{kDa}$ protein from photosystem II upon heating to $47^{\circ} \mathrm{C}$ causes inactivation of oxygen evolution likely due to $\mathrm{Ca}$ release from the Mn-complex. Photosynth. Res. 84, 231-237 (2005).

71 Barra, M. et al. Intermediates in assembly by photoactivation after thermally accelerated disassembly of the manganese complex of photosynthetic water oxidation. Biochemistry 45, 14523-14532 (2006).

72 Zaharieva, I. et al. Room-temperature energy-sampling K $\beta$ X-ray emission spectroscopy of the $\mathrm{Mn}_{4} \mathrm{Ca}$ complex of photosynthesis reveals three manganese-centered oxidation steps and suggests a coordination change prior to $\mathrm{O}_{2}$ formation. Biochemistry 55, 4197-4211. (2016). Haumann, M. et al. Structural and oxidation state changes of the photosystem II manganese complex in four transitions of the water oxidation cycle $\left(S_{0} \rightarrow S_{1}, S_{1} \rightarrow S_{2}, S_{2} \rightarrow S_{3}\right.$, and $S_{3,4} \rightarrow$ $\mathrm{S}_{0}$ ) characterized by $\mathrm{X}$-ray absorption spectroscopy at $20 \mathrm{~K}$ and room temperature. Biochemistry 44, 1894-1908 (2005).

74 Klockenkämper, R. Total Reflection X-ray Fluorescence Analysis. (Wiley, London, UK, 1996).

75 Shevchenko, D. et al. Water oxidation by manganese oxides formed from tetranuclear precursor complexes: the influence of phosphate on structure and activity. Phys. Chem. Chem. Phys. 16, 11965-11975 (2014).

76 Dau, H., Liebisch, P. \& Haumann, M. X-ray absorption spectroscopy to analyze nuclear geometry and electronic structure of biological metal centers - potential and questions examined with special focus on the tetra-nuclear manganese complex of oxygenic photosynthesis. Anal. Bioanal. Chem. 376, 562-583 (2003).

77 Rehr, J. J., Kas, J. J., Vila, F. D., Prange, M. P. \& Jorissen, K. Parameter-free calculations of Xray spectra with FEFF9. Phys. Chem. Chem. Phys. 12, 5503-5513 (2010).

78 Dittmer, J. \& Dau, H. On the influence of multiple scattering contributions to the extended Xray absorption fine structure (EXAFS) spectra of the photosystem II manganese complex. Ber. Bunsenges. Phys. Chem. 100, 1993-1998 (1996). 